\title{
Erosion depth of sand from an immobile gravel bed
}

\author{
ROGER KUHNLE, DANIEL WREN \& EDDY LANGENDOEN \\ National Sedimentation Laboratory, USDA-Agricultural Research Service, 598 McElroy Drive, Oxford, Mississippi \\ 38655 USA \\ roger.kuhnle@ars.usda.gov
}

\begin{abstract}
This study was conducted to improve prediction of the depth of erosion of sand $\left(\mathrm{D}_{50}=0.3-0.9 \mathrm{~mm}\right)$ from immobile gravel $\left(\mathrm{D}_{50}=36.1 \mathrm{~mm}\right)$ under steady uniform flows with bed shear stresses from 0.1 to 0.9 of that required to entrain the gravel. This situation, often encountered downstream of dams, has important implications for habitat restoration. Steady uniform flows were imposed on a flume channel containing a mixture of sand and gravel until sediment concentrations in the flow exiting the channel became small. The elevation of sand relative to gravel was measured after each experiment and compared poorly to calculated depths from published relationships whose predictions were based in part on the equivalent grain roughness of the bed. An improved predictive relationship was developed by using the cumulative distribution function of the surface gravel elevations to scale the shear velocity available for transporting sand from the gravel substrate.
\end{abstract}

Key words erosion; sand; immobile gravel

\section{INTRODUCTION}

Channels downstream of dams generally have reduced flood flows due to storage in their reservoirs. This may cause gravel in the bed of the channel downstream of the dam to become immobile and filled with sand delivered from tributaries downstream of the dam. Infilling of the gravel substrate renders the bed material a poor habitat for many benthic organisms, e.g. macroinvertebrates and salmonid fish. Accurate predictions of the depth of the sand that can be eroded out of the gravel without causing gravel mobilization are currently difficult to make. Based on a series of measurements of the pressure distribution within a gravel bed, Detert and Parker (2010) developed the following expression to predict the washout depth of sand from an immobile gravel bed:

$$
\frac{\lambda_{c}}{k_{s}}=-1.0 \ln \left(\frac{u_{*}}{v_{f}}\right)
$$

where $\lambda_{c}(\mathrm{~m})$ is the depth below the top of gravel (negative) from which sand is cleaned out, $k_{s}(\mathrm{~m})$ is the equivalent grain roughness, $u *(\mathrm{~m} / \mathrm{s})$ is the shear velocity of the flow at the bed, and $v_{f}(\mathrm{~m} / \mathrm{s})$ is the fall velocity of the sand. Ambiguities in the determination of the equivalent grain roughness makes implementation of equation (1) problematic.

There is a lack of published data on the depth to which that sand may be eroded from an immobile gravel bed under known flow and sediment conditions. In order to provide data for developing an improved relationship among flow parameters, sand elevation and sand cleanout depth, a series of laboratory flume experiments was performed with bed shear stresses ranging from 0.1 to 0.9 times the critical shear stress for entrainment of the experimental gravel substrate.

\section{EXPERIMENTS}

Experiments were conducted at the National Sedimentation Laboratory in a flume channel with adjustable slope that was $10 \mathrm{~m}$ long, $0.30 \mathrm{~m}$ wide, by $0.60 \mathrm{~m}$ deep, in which only the water was recirculated. Two sands were used in the experiments. One ranged from 0.1 to $0.5 \mathrm{~mm}$ in diameter, with a median diameter of $0.30 \mathrm{~mm}$ and $\left(\mathrm{D}_{84} / \mathrm{D}_{16}\right)^{1 / 2}=1.37$. The other sand ranged from 0.2 to 2.0 $\mathrm{mm}$, with a median diameter of $0.86 \mathrm{~mm}$ and $\left(\mathrm{D}_{84} / \mathrm{D}_{16}\right)^{1 / 2}=1.39$. The gravel substrate consisted of a randomly placed $0.2 \mathrm{~m}$ thick layer, with the first $0.75 \mathrm{~m}$ from the upstream end of the channel glued down to prevent entrainment in high shear stresses caused by the developing boundary layer. The gravel ranged from 27 to $62 \mathrm{~mm}$ in diameter with a median diameter of $36.10 \mathrm{~mm}$ and $\left(\mathrm{D}_{84} / \mathrm{D}_{16}\right)^{1 / 2}=1.17$. 
Depth of flow in the flume experiments ranged from 0.196 to $0.213 \mathrm{~m}$ and was calculated as the difference between the height of the bed and the water surface as measured from stream parallel transects down the middle of the channel over the downstream $7.5 \mathrm{~m}$ using an acoustic distance measuring instrument, which was mounted on a carriage that rode on rails above the channel. Water surface slope was calculated as the sum of the slope of the water surface transect relative to the flume rails and the slope of the flume channel. Water discharge in the flume channel was measured using a calibrated 90-degree elbow meter in the $0.20 \mathrm{~m}$ diameter pipe from the variable speed pump that delivered water to the head box of the experimental channel. The pressure across the elbow meter was recorded by a pressure transducer and was logged by computer throughout the experiments. The water exited the channel through a $0.30 \mathrm{~m}$ square vertical pipe which led to a water-filled $0.9 \mathrm{~m}$ square sump. The sump ran the length of the channel and acted as a return for the water, as well as a location for sand deposition. Seven steady and uniform flows, with discharges nominally from 22 to $77 \mathrm{~L} / \mathrm{s}$, were imposed on the gravel and sand beds. The shear velocity $\left(u_{*}, \mathrm{~m} / \mathrm{s}\right)$ of each experiment was calculated as:

$$
u_{*}=\sqrt{\frac{\tau_{b}}{\rho}}
$$

where $\rho\left(\mathrm{kg} / \mathrm{m}^{3}\right)$ is the density of the water and $\tau_{b}(\mathrm{~Pa})$ is the bed shear stress which was calculated using the relation of Vanoni and Brooks (1957) as modified by Chiew and Parker (1994). For each experimental run, the flow depth and slope were chosen, and uniform flow and flow depth were maintained by adjusting the pump speed and the rate of water exiting the flume channel with a flow gate at the bottom of the exit pipe of the flume.

The concentration of the sand in the flow exiting the channel was sampled continuously using a nozzle (inside diameter of $15.9 \mathrm{~mm}$ ) mounted in the centre of the vertical square return pipe above the sump and $0.15 \mathrm{~m}$ below a set of static mixing structures. The four $0.15 \mathrm{~m}$ long static mixing modules were mounted at 90 degree angles to one another and ensured that the sediment and water samples were representative. The homogeneity of the sand concentration was established prior to the beginning of experiments with a series of samples collected across the vertical return pipe. All samples were collected isokinetically by adjusting the flow through the sampling nozzle with a variable speed pump to match the local flow velocity in the return pipe. Sand was sampled continuously by passing the mixture of water and sediment collected from the sampling nozzle over a sieve with $62 \mu \mathrm{m}$ square openings. Sand concentrations, in all cases, were high at the beginning of each experiment and gradually decreased with time as the experiment progressed.

Enough sand was added to just cover the gravel bed at the beginning of each of the two series of experiments. Each experimental series began with the lowest flow discharge. Experimental run times ranged from 47 to 160 hours. After measuring the elevations of the sand and gravel substrate using a point gauge, the next experimental run was conducted with the next highest flow being imposed on the bed that was established during the previous run. This procedure was repeated until all seven flows were completed in each of the two experimental series.

\section{RESULTS}

The depth to which the sand was eroded from the gravel bed ranged from 22 to $71 \mathrm{~mm}$ for the $0.30 \mathrm{~mm}$ sand and from 16 to $52 \mathrm{~mm}$ for the $0.86 \mathrm{~mm}$ sand (Fig. 1). Also shown in Fig. 1 are calculated values for the washout depth using equation (1) from Detert and Parker (2010). Equation (1) yielded predictions of zero scour for the coarser sand, because the shear velocity was less than the sand fall velocity in all seven of the experiments. Another issue with the use of equation (1) is the estimate of the equivalent grain roughness $\left(k_{\mathrm{s}}\right)$ of the gravel substrate. For the calculated values shown in Fig. 1, the median diameter of the gravel was used as an estimate of $k_{s}$. A value of $k_{\mathrm{s}}$ of $2.6 \times \mathrm{D}_{50}$ was assessed but yielded predictions greater than the measured washout depths. 


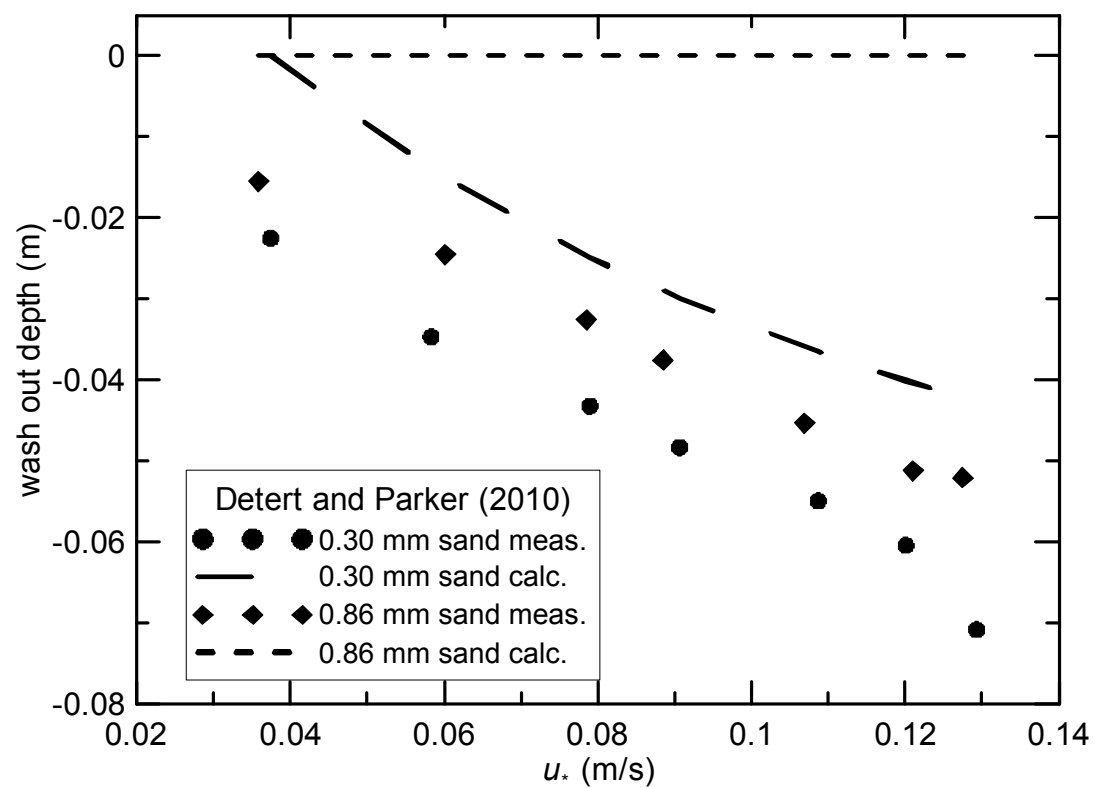

Fig. 1 Measured washout depths from experiments and calculated values from equation (1) of Detert and Parker (2010).

\section{Revised prediction algorithm}

Previous studies have established that the shear stress below the top of the gravel substrate decreases in a manner related to the cumulative distribution function of the surface gravel heights (Wren et al., 2011; Kuhnle et al., 2013; Wren et al., 2014). This cumulative distribution function has been termed the roughness geometry function (RGF) (Nikora et al., 2001; Pellachini, 2011). It has been shown that the transport of sand over immobile substrates of both gravel (Kuhnle et al., 2013) and cobbles (Wren et al., 2014) may be predicted by scaling the bed shear stress by a function of the RGF evaluated at the mean depth of the sand layer relative to the top of the substrate. A similar approach was taken here to scale the shear velocity at the bed by using the RGF. The RGF was calculated from a high-resolution laser scan of the gravel bed which was collected before the sand was added to the experimental channel (Fig. 2). The RGF $(A(\mathrm{z}))$ was used to scale the shear velocity in the bed as follows:

$$
u_{*_{s}}\left(z_{i}\right)=\sqrt{\frac{A\left(z_{i}\right) \tau_{b}}{\rho}},
$$

where $u_{\mathrm{s}}(\mathrm{m} / \mathrm{s})$ is the shear velocity at the elevation of the sand interface. The erosion of sand in the gravel was assumed to proceed to the depth where the fall velocity of the sand and local shear velocity were equal:

$$
u_{*_{S}}\left(z_{i}\right)=v_{f}
$$

To predict the washout depth for sand, the value of $A\left(z_{w}\right)$ was calculated as:

$$
A\left(z_{w}\right)=\frac{v_{f}^{2} \rho}{\tau_{b}}
$$

and the RGF was evaluated to yield $z_{w}$. The relation of Wu and Wang (2006) was used to calculate the fall velocity of the sand. The washout depth relative to the top of the gravel, $\lambda_{c}$, was calculated as:

$$
\lambda_{c}=z_{w}-z_{100}
$$

which results in negative values for predicted washout elevations below the top of the gravel. The predicted values for the washout depth compare closely to the measured values of the $0.30 \mathrm{~mm}$ 


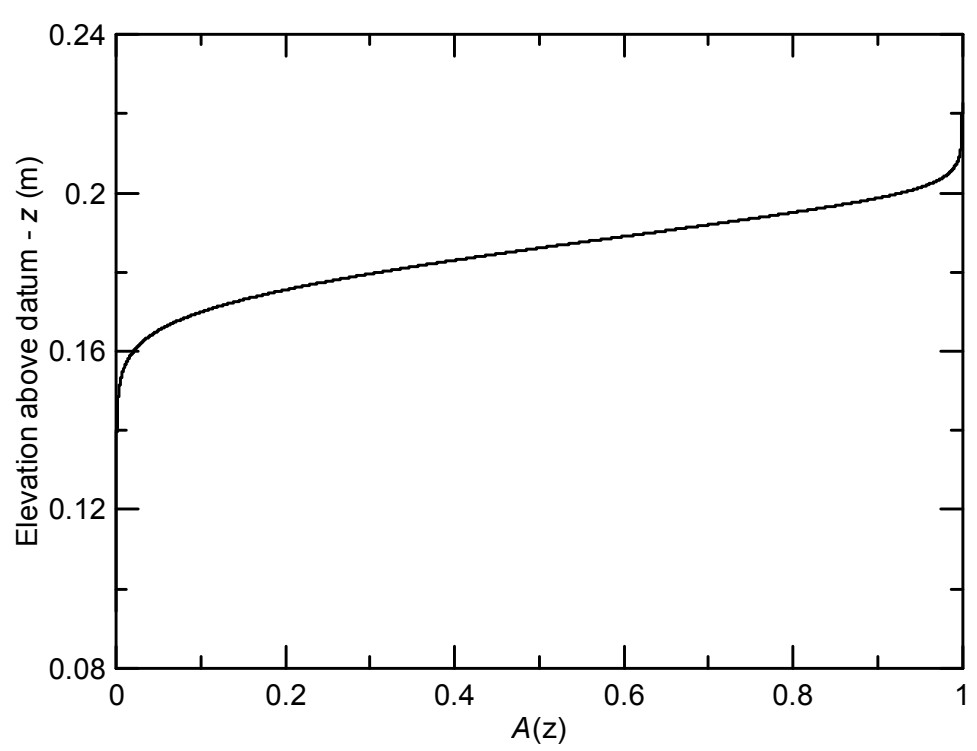

Fig. 2 Cumulative distribution function of gravel elevations $(\mathrm{A}(\mathrm{z}))$.

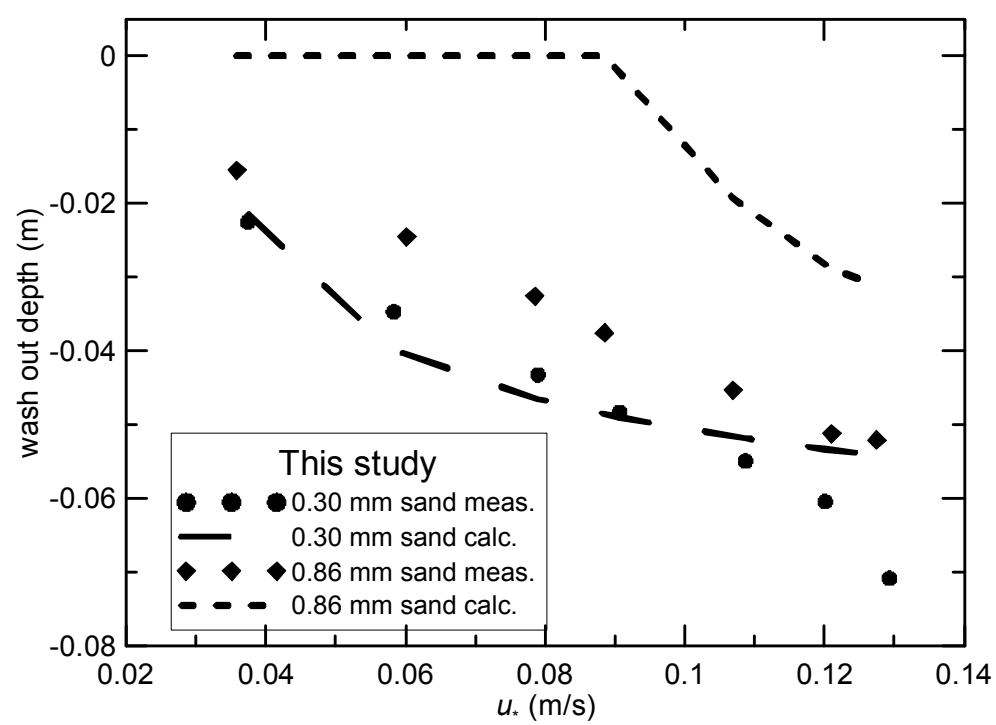

Fig. 3 Measured washout depths from the experiments and calculated values from equations (5) and (6).

sand, while the comparison to the data for the $0.86 \mathrm{~mm}$ sand is not as good (Fig. 3). For the 0.86 $\mathrm{mm}$ sand, it was determined that a good fit to the measured data resulted if the criterion for the suspension of the sand was assumed to be:

$$
u_{*_{s}}\left(z_{i}\right)=\frac{v_{f}}{2}
$$

rather than equation (4). This resulted in:

$$
A\left(z_{w}\right)=\frac{v_{f}^{2}(\rho)}{4\left(\tau_{b}\right)} .
$$

Equation (8) yielded a dramatic improvement in the prediction of washout depth for the $0.86 \mathrm{~mm}$ sand, but caused an over prediction of the washout depth for the $0.30 \mathrm{~mm}$ sand (Fig. 4).

It is apparent that two separate erosion criteria appear to be functioning for the fine and coarse sands used in this experimental study. There apparently is a change in the relation for suspension of sand from the gravel which is dependent on the grain size of the sand. This will be explored further in future experimental studies. 


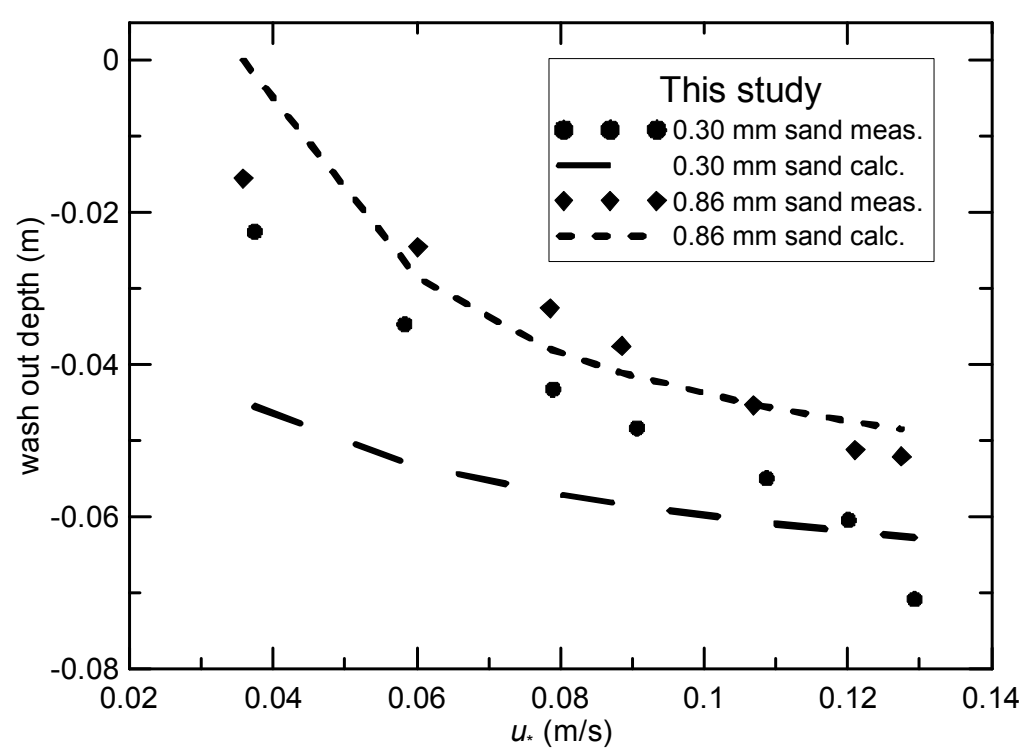

Fig. 4 Measured washout depths from the experiments and calculated values from equations (7) and (8).

\section{CONCLUSIONS}

Experiments on the erosion of sands with median diameters of 0.30 and $0.86 \mathrm{~mm}$ have been completed and have illustrated the difficulty of predicting the washout depth of sand from a gravel substrate. The relation of Detert and Parker (2010) predicted that the coarser sand would not be eroded from the gravel in these experiments. Predictions using the Detert and Parker (2010) relationship were too low if the $\mathrm{D}_{50}$ of the gravel was used, and too high if $2.6 \mathrm{D}_{50}$ was used as the equivalent grain roughness. Accurate prediction of the equivalent grain roughness is a problem with using the Detert and Parker (2010) relationship.

A new relationship to predict the washout depth of sand was proposed on the basis of this study which used the cumulative distribution function of the gravel surface to predict the distribution of shear velocity in the gravel below the surface. This relationship shows promise; there appears to be, however, a dependence on the size of the sand that is not compensated for in this relationship.

Acknowledgements The experiments of this study could not have been completed without the capable assistance of John Cox. Reviews by Mary Nichols, Rob Wells and Adrian Collins resulted in an improved manuscript.

\section{REFERENCES}

Chiew, Y. M. \& Parker, G. (1994) Incipient motion on non-horizontal slopes. Journal of Hydraulic Research, 32(5), 649-660. Detert, M. \& Parker, G. (2010) Estimation of the washout depth of fine sediments from a granular bed. Journal of Hydraulic Engineering 136(10), 790-793.

Kuhnle, R. A., et al. (2013) Sand transport over an immobile gravel substrate. Journal of Hydraulic Engineering 139(2), 167-176.

Nikora, V., et al. (2001) Spatially averaged open-channel flow over rough bed. Journal of Hydraulic Engineering 127(2), 123133.

Pellachini, C. (2011) Modelling fine sediment transport over an immobile gravel bed. PhD Thesis, Department of Engineering, University of Trento, Trento, Italy, $120 \mathrm{p}$.

Vanoni, V.A. \& Brooks, N.H. (1957) Laboratory studies of the roughness and suspended load of alluvial streams. California Inst. of Technology Sedimentation Laboratory, U.S. Army Engineer Division, M.R.D. Sediment Series, no.11, 121 p.

Wren, D. G., et al. (2014) Turbulent flow and sand transport over a cobble bed in a laboratory flume. Journal of Hydraulic Engineering 140(4), 04014001.

Wren, D. G., Langendoen, E. J. \& Kuhnle, R. A. (2011) Effects of sand addition on turbulent flow over an immobile gravel bed. Journal of Geophysical Research, Earth Surface 116, F01018,

Wu, W. \& Wang, S.S.Y. (2006) Formulas for sediment porosity and settling velocity. Journal of Hydraulic Engineering 132(8), $858-862$. 